\title{
PENGARUH DISIPLIN DAN PELATIHAN KERJA TERHADAP KINERJA KARYAWAN PADA PT INDOMARCO PRISMATAMA CABANG TANGERANG 2
}

\author{
Mutmainnah \\ Universitas Pamulang, Tangerang Selatan, Banten, Indonesia \\ dosen01720@unpam.ac.id
}

\begin{abstract}
Abstrak
Tujuan penelitian ini adalah untuk mengetahui kondisi disiplin kerja, pelatihan kerja dan kinerja karyawan pada PT. Indomarco Prismatama Cabang Tangerang 2, untuk mengetahui pengaruh disiplin kerja terhadap kinerja karyawan pada PT. Indomarco Prismatama Cabang Tangerang 2, untuk mengetahui pengaruh pelatihan kerja terhadap kinerja karyawan pada PT. Indomarco Prismatama Cabang Tangerang 2, untuk mengetahui pengaruh disiplin kerja dan pelatihan kerja secara bersamasama terhadap kinerja karyawan pada PT. Indomarco Prismatama Cabang Tangerang 2. Penelian bersifat asosiatif dengan pendekatan kuantitatif. Sampel yang digunakan dalam penelitian ini sebanyak 112 responden. Tehnik pengumpulan data dengan cara menyebar kuisioner, dan tehnik analisis data dengan uji validitas, reliabilitas uji asumsi klasik, analisis linier sederhana, analisis regresi berganda, koefisien korelasi, koefisien determinasi, uji hipotesis, uji $\mathrm{F}$ dan uji $t_{\text {hitung }}$. Hasil penelitian sebagai berikut : Secara bersama-sama terdapat pengaruh positif dan signifikan disiplin dan pelatihan kerja terhadap kinerja karyawan pada PT. Indomarco Prismatama Cabang Tangerang 2. Hal ini dapat dibuktikan dari persamaan regresi linier berganda yaitu $Y=4,893+0,528 X_{1}+0,800 X_{2}$ nilai koefisien korelasi sebesar 0,908 dan nilai determinasi 82,5\% dan nilai nilai $\mathrm{F}$ hitung 256,308 > F tabel 3,08 dengan signifikansi $0,000<0,05$. dengan demikian keputusan yang diambil Ho ditolak dan Ha diterima. Yang berarti variabel disiplin dan pelatihan kerja mampu mempengaruhi variabel kinerja karyawa, diperoleh nilai koefisien determinasi atau $\mathrm{R}$ square sebesar 0,825 artinya $82,5 \%$ variabel terikat yaitu kinerja karyawan $(\mathrm{Y})$ variasianya dapat dijelaskan oleh variabel disiplin kerja $\left(\mathrm{X}_{1}\right)$ dan pelatihan kerja $\left(\mathrm{X}_{2}\right)$ dan sisanya sebesar 17,5\% dijelaskan diluar variabel yang digunakan.
\end{abstract}

Kata Kunci: Disiplin Kerja, Pelatihan Kerja, Kinerja Karyawan

\section{Abstract}

The purpose of this study was to determine the conditions of work discipline, job training and employee performance at PT. Indomarco Prismatama Tangerang Branch 2, to determine the effect of work discipline on employee performance at PT. Indomarco Prismatama Tangerang Branch 2, to determine the effect of job training on employee performance at PT. Indomarco Prismatama Tangerang Branch 2, to determine the effect of joint work discipline and work training together on employee performance at PT. Indomarco Prismatama Tangerang Branch 2. Research is associative with a quantitative approach. The sample used in this study was 112 respondents. Data collection techniques by distributing questionnaires, and data analysis techniques using validity test, reliability test of classic assumptions, simple linear analysis, multiple regression analysis, correlation coefficient, determination coefficient, hypothesis test, F test and t_count test. The results of the study are as follows: Together there is a positive and significant influence of discipline and job training on employee performance at PT. Indomarco Prismatama Tangerang Branch 2. This can be proven from the multiple linear regression equation $Y$ $=4.893+0.528 \mathrm{X}_{1}+0.800 \mathrm{X}_{2}$ the correlation coefficient value is 0.908 and the determination value is $82.5 \%$ and the calculated $F$ value is $256.308>F$ table 3.08 with significance of $0,000<0.05$. thus Ho's decision was rejected and Ha was accepted. Which means that the discipline and work training variables are able to influence employee performance variables, the coefficient of determination or $R$ square value of 0.825 means that $82.5 \%$ of the dependent variable ie employee performance $(Y)$ variations can be explained by the work discipline variable $\left(X_{I}\right)$ and work training $\left(X_{2}\right)$ and the remaining $17.5 \%$ is explained outside the variables used.

Keywords: Work Discipline, Job Training, Employee Performance 


\section{PENDAHULUAN}

Perkembangan bisnis eceran (retailing) dalam negeri saat ini mengalami pertumbuhan yang sangat pesat, sehingga dengan sewajarnya menimbulkan persaingan yang ketat pila. Sejak sepuluh tahun terakhir perkembangan usaha eceran mengalami perubahan yang sangat besar dalam operasionalnya. Salah satu fenomena menarik yang muncul dari moderitas masyarakat kota saat ini , adalah gaya hidup mereka yang melakukan aktivitas belanja. Belanja baik untuk keperluan konsumsi sehari-hari (kebutuhan primer) dan konsumsi kebutuhan lainnya, seperti kebutuhan sandang, seperti pakaian dan kelengkapannya (kebutuhan sekunder).

Hasibuan (2013 : 23), Disiplin merupakan fungsi manajemen sumbar daya manusia (MSDM) yang terpenting dan kunci terwujudnya tujuan karena tanpa disiplin yang baik maka sulit terwujud tujuan maksimal. Disiplin kerja karyawan yang sebaik-baiknya harus ditanamkan dalam diri setiap karyawan, sebaiknya bukan atas paksaan atau tuntutan semata akan tetapi didasarkan atas kesadaran dari dalam diri setiap karyawan. Untuk mendapatkan disiplin kerja yang baik, karyawan harus taat pada aturan waktu, taat terhadap aturan perilaku dalam bekerja dan taat pada peraturan perusahaan yang sudah dibuat dan disepakati bersama.

Menurut Sikula dalam Mangkunegara (2013:44) Pelatihan adalah suatu proses pendidikan jangka pendek yang menggunakan prosedur sistematis dan terorganisir dimana pegawai non managerial mempelajari pengetahuan dan keterampilan teknis dalam tujuan terbatas.

Menurut Anwar Prabu Mangkunegara (2013 : 67) Kinerja adalah suatu hasil kerja yang dicapai seseorang secara kualitas dan kuantitas dalam melaksanakan tugas-tugas sesuai dengan tanggung jawab yang diberikan kepadanya.

Berdasarkan pengamatan penulis bahwa karyawan yang bekerja di perusahaan tersebut belum memenuhi standar kehadiran dan keterlambatan.

Adapun masalah yang berkaitan dengan disiplin kerja dan kinerja karyawan yang saat ini ada di PT. Indomarco Prismatama Cabang Tangerang 2 yaitu kurangnya pengawasan pada saat jam kerja yang membuat setiap karyawan bebas melakukan kegiatan yang tidak ada hubungannya dengan pekerjaan, dan kegiatan lain yang tidak ada hubungannya dengan pekerjaan. Kurangnya disiplin karyawan yang mempengaruhi kinerja karyawan menjadi belum optimal, terutama dengan kehadiran dan disiplin PT. Indomarco Prismatama Cabang Tangerang 2, masih banyak karyawan yang tidak tepat waktu bahkan tidak hadir dengan berbagai alasan dan istirahat melebihi dari waktu yang telah diberikan, yang membuat divisi tersebut tidak stabil, yang melibatkan tingkat absensi pegawai kurang baik dan manajemen waktu yang buruk. Akibat masalah kurangnya disiplin tersebut target yang telah diberikan setiap bulannya tidak tercapai dengan maksimal.

Pelatihan yang dilakukan oleh suatu perusahaan dapat berlangsung secara internal perusahaan ataupun eksternal perusahaan, yang dimaksud dengan internal perusahaan adalah para karyawan yang membutuhkan pelatihan dapat mengikuti program-program pelatihan yang telah dibuat oleh perusahaan yang pelaksanaannya dilakukan didalam perusahaan tersebut. Dan yang dimaksud dengan eksternal perusahaan adalah perusahaan membuat program pelatihan yang dibutuhkan oleh karyawan dengan bekerjasama dengan suatu organisasi atau beberapa organisasi yang memiliki materi ataupun fasilitas yang dibutuhkan perusahaan untuk pelaksanaan pelatihan yang dibutuhkan oleh karyawan di perusahaan tersebut.

Tujuan yang diharapkan dalam pelaksanaan pelatihan bagi karyawan adalah meningkatkan kapasitas dan minat karyawan untuk belajar dengan mendorong komitmen dan menyediakan aksebilitas pada proses pembelajaran yang terus menerus. Namun jumlah karyawan yang mengikuti pelatihan tiap tahunnya tidak sesuai dengan pertambahan karyawan, padahal pelatihan 
sangat dibutuhkan bagi seluruh karyawan, mulai dari tingkat yang sangat bawah sampai yang tingkat atas. Sehingga tujuan perusahaan akan lebih tercapai dengan memiliki sumber daya manusia yang terlatih.

Berdasarkan latar belakang permasalahan yang ada diatas, maka penulis tertarik untuk mengangkat tema penelitian dengan berjudul "Pengaruh Disiplin dan Pelatihan kerja terhadap Kinerja Karyawan Pada PT. Indomarco Prismatama Cabang Tangerang $2^{\prime \prime}$.

\section{TINJAUAN PUSTAKA}

\section{Disiplin Kerja}

Menurut Hasibuan (2013:193), disiplin adalah fungsi operatif keenam dari manajemen sumber daya manusia, kedisplinan merupakan fungsi operatif manejeman sumber daya manusia yang terpenting karena semakin baik disiplin pegawai, semakin tinggi prestasi kerja yang dapat dicapai.

2. Pelatihan Kerja

Menurut Sikula dalam Mangkunegara (2013:44) Pelatihan adalah suatu proses pendidikan jangka pendek yang menggunakan prosedur sistematis dan terorganisir dimana pegawai non managerial mempelajari pengetahuan dan keterampilan teknis dalam tujuan terbatas.

\section{Kinerja Karyawan}

Kinerja menurut Wilson Bangun (2012:231) adalah kinerja atau (performance) adalah hasil pekerjaan yang dicapai seseorang berdasarkan persyaratan-persyaratan pekerjaan (job requirement) Suatu pekerjaan mempunyai persyaratan tertentu untuk dapat dilakukan dalam mempunyai tujuan yang disebut juga sebagai standar pekerjaan (job standart).

\section{METODE}

Populasi dalam penelitian ini berjumlah 156 responden karyawan PT Indomarco Prismatama Cabang Tangerang 2. Sampel dalam penelitian ini berjumlah 156 responden. Jenis penelitian yang dipakai adalah kuantitatif, dimana tujuannya adalah untuk mengetahui pengaruh antara variabel bebas terhadap variabel terikat baik parsial maupun simultan. Dalam menganalisis data digunakan uji instrumen, uji asumsi klasik, regresi, koefisien korelasi, koefisien determinasi dan uji hipotesis.

\section{HASIL DAN PEMBAHASAN}

\section{Analisis Regresi Linear Sederhana}

a. Pengaruh disiplin kerja terhadap kinerja karyawan

Berdasarkan hasil perhitungan regresi diperoleh nilai $t_{\text {hitung }}$ variabel disiplin kerja, dimana $t_{\text {hitung }}$ sebesar 2,738dengan signifikan $\mathrm{a}=0,05$ sedangkan $t_{\text {tabel }}$ sebesar 1,981 maka diperoleh $t_{\text {hitung }}>$ dari $t_{\text {tabel }}$ dan $t_{\text {sig }}<0,05$ atau 2,738 $>1,981$ dan 0,004 $<0,05$, hal ini berarti bahwa disiplin kerja secara parsial berpengaruh terhadap kinerja karyawan karena nilai signifikan dibawah 0,05 dengan demikian dapat disimpulkan bahwa disiplin kerja berpengaruh signifikan terhadap kinerja karyawan.

b. Pengaruh pelatihan kerja terhadap kinerja karyawan

Berdasarkan hasil perhitungan regresi diperoleh nilai $t_{\text {hitung }}$ variabel pelatihan kerja, dimana

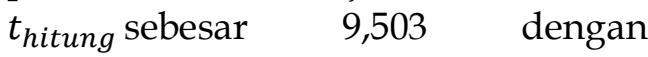
signifikan $\quad \mathrm{a}=0,05 \quad$ sedangkan $t_{\text {tabel }}$ sebesar 1,981 maka diperoleh $t_{\text {hitung }}>$ dari $t_{\text {tabel }}$ dan $t_{\text {sig }}<0,05$ atau $9,503>1,981$ dan $0,000<0,05$, hal ini berarti bahwa pelatihan kerja secara parsial berpengaruh terhadap kinerja karyawan karena nilai signifikan dibawah 0,05 dengan demikian dapat disimpulkan bahwa pelatihan kerja berpengaruh signifikan terhadap kinerja karyawan.

c. Pengaruh disiplin dan pelatihan kerja terhadap kinerja karyawan.

Berdasarkan hasil pengujian pengaruh disiplin dan pelatihan kerja secara bersama-sama memiliki pengaruh signifikan terhadap kinerja karyawan. Berdasarkan hasil perhitungan SPSS diperoleh nilai 
$F_{\text {hitung }}=256,308$ dengan signifikansi F sebesar 0,00 dengan menggunakan tingkat signifikansi 0,05 maka nilai tabel dengan $\mathrm{dk}=\mathrm{n}-\mathrm{k}-1=(112-2$ 1=109) diperoleh $F_{\text {tabel }} 3,08$ sebesar nilai signifikansi tersebut masih berada dibawah nilai signifikansi yang ditetapkan sebesar 0,05 sehingga disimpulkan bahwa disiplin dan pelatihan kerja berpengaruh signifikan terhadap kinerja karyawan.

\section{PENUTUP}

\section{Kesimpulan}

a. Kondisi disiplin kerja pada PT. Indimarco Prismatama Cabang Tangerang 2 adalah baik, hal ini dapat terlihat dari akumulasi rata-rata skor sebesar 4,03 masuk pada rentang interval 3,40 - 4,19 yang memiliki interprestasi baik. Pelatihan kerja pada PT. Indomarco Prismatama Cabang Tangerang 2 adalah baik, hal ini dapat dilihat dari akumulasi ratarata skor sebesar 3,97 masuk pada rentang interval 3,40 - 4,19 yang memiliki interprestasi baik. Kinerja karyawan pada PT. Indomarco Prismatama Cabang Tangerang adalah baik, hal ini dapat dilihat dari skor rata-rata sebesar 3,94 masuk pada interval 3,40 - 4,19 yang memiliki interprestasi baik.

b. Terdapat pengaruh yang positif dan signifikan disiplin $\left(X_{1}\right)$ terhadap kinerja karyawan (Y) pada PT. Indomarco Prismatama Cabang Tangerang 2. Hal ini dapat dibuktikan dari nilai regresi linier berganda sebesar $0,528 X_{1}$ nilai koefisien korelasi sebesar 0,823 dan koefisien determinasi sebesar $67,8 \%$ dan $t_{\text {hitung }} 2,738>t_{\text {tabel }} 1,981$ dengan signifikansi 0,004<0,05.

c. Terdapat pengaruh yang positif dan signifikan pelatihan $\left(\mathrm{X}_{2}\right)$ terhadap kinerja karyawan $(\mathrm{Y})$ pada PT. Indomarco Prismatama Cabang Tangerang 2. Hal ini dapat dibuktikan dari nilai regresi linier berganda sebesar $0,800 \mathrm{X}_{2}$ nilai koefisien korelasi sebesar 0,908, dan koefisien determinasi sebesar $82,4 \%$ dan $t_{\text {hitung }}$ $9,503>t_{\text {tabel }} 1,981$ dengan signifikansi $0,000<0,05$.

d. Secara bersama-sama terdapat pengaruh positif dan signifikan disiplin dan pelatihan kerja terhadap kinerja karyawan pada PT. Indomarco Prismatama Cabang Tangerang. Hal ini dapat dibuktikan dari persamaan regresi linier berganda yaitu $Y=4,893$ $+0,528 \mathrm{X}_{1}+0,800 \mathrm{X}_{2}$ nilai koefisien korelasi sebesar 0,908 dan nilai determinasi $82,5 \%$ dan nilai nilai $\mathrm{F}$ hitung 256,308 $>\mathrm{F}$ tabel 3,08 dengan signifikansi $0,000<0,05$.

\section{Saran}

a. Pada indikator taat sanksi hukuman maka penulis menyarankan, agar pemimpin harus lebih meningkatkan sanksi dan hukuman yang jelas agar ditakuti oleh karyawan dan karyawan tidak melakukan tindak indisipliner.

b. Pada indikator peserta maka penulis meyarankan agar karyawan dalam mengikuti pelatihan harus berusaha dan bersungguh-sungguh semaksimal mungkin memperhatikan setiap pelatihan yang berlangsung agar para karyawan mendapatkan ilmu yang dapat meningkatkan kecakapan dalam bejkerja.

c. Pada indikaror kemampuan kerja sama maka penulis menyarankan agar karyawan yang lebih senior mengajarkan hal-hal yang perlu diberikan kepada karyawan yang lebih junior agar para karyawan yang baru dapat bekerja secara mandiri.

\section{DAFTAR PUSTAKA}

G.R Terry, (2011). “Manajemen Dasar Pengertian dan Masalah", edisi revisi, Cetakan 1, Penerbit Bumi Aksara. Jakarta. 
Hasibuan, M. (2012). Manajemen Sumber Daya manusia. Jakarta: PT Bumi Aksara.

Hasibuan, M. S. (2011). Manajemen Sumber Daya Manusia. Jakarta: Bumi Aksara.

Kustini, E., et al. (2021). Pengaruh Keterampilan Kerja Dan Lingkungan Kerja Terhadap Kinerja Karyawan Pada PT. Garuda Daya Pratama Sejahtera (Garuda Indonesia Group). Jurnal Ilmiah PERKUSI, 1(3), 305-314.

Luthans, Fred.

(2016).

"PerilakuOrganisasi". (Alih Bahasa V.A Yuwono, dkk), Edisi Bahasa Indonesia, Yogyakarta: ANDI.

Mangkunegara, Anwar Prabu. Manajemen Sumber Daya Manusia Perusahaan. Bandung : PT. Remaja Rosdakarya. 2013

Mathis Robert L. dan Jackson John H (2016). "Human Resource Management". Alih Bahasa. Salemba Empat. Jakarta.

Nurjaya, N., et al. (2020). Edupreneurship management in shaping the nation's character. Jurnal Konseling dan Pendidikan, 8(3), 198-206.

Santoso, Singgih, "SPSS StatistikParametik" Cetakan Kedua, PT. Elek Media, 2015.

Sedarmayanti. "Manajemen Sumber Daya Manusia, Reformasi Birokrasi dan Manajemen Pegawai Negeri Sipil",
Cetakan Kelima, PT Refika Aditama, Bandung, 2014.

Simamora, Henry. (2014). "Manajemen Sumber Daya Manusia". Cetakan Kedua, STIE YKPN, Yogyakarta.

Sugiyono. (2015). Metode Penelitian Manajemen, CV Alfabeta, Bandung.

Sunarsi, D. (2018). Pengaruh Motivasi Dan

Disiplin Terhadap Produktivitas

Kerja Karyawan Pada PT. Nadi Suwarna Bumi. Jurnal Semarak, 1(1).

Sunarsi, D. (2018). Pengaruh Rekrutmen, Seleksi Dan Pelatihan Terhadap Produktivitas Kerja Karyawan. Kreatif: Jurnal Ilmiah Prodi Manajemen Universitas Pamulang, 6(1), 14-31.

Sunarsi, D. (2019). Seminar Sumber Daya Manusia. Tangerang Selatan: Unpam Press

Suwanto, S., et al. (2021). Pengaruh Motivasi Dan Pengalaman Kerja Terhadap Produktivitas Karyawan Pada Happy Restaurant Di Bandung. Jurnal Ekonomi Efektif, 3(4), 546-554.

Suwatno dan Doni Juni Priyansa. (2012). Manajemen Sumber Daya Manusia. CV Alfabeta Bandung.

Veithzal Rivai, "Proses Arti Pelatihan". Jakarta, 2014.

Wibowo, "Manajemen Kinerja", PT. Raja Grafindo Persada, Jakarta, 2014. 